\title{
Mothers Accused and Abused Addressing Complex Psychological Needs
}

\author{
Angela Foster \\ London: Routledge, 2018, 178 pp., ISBN 9781138095847, £25.99 (pbk)
}

Reviewed by: Dr. Yohai Hakak, Senior Lecturer, Brunel University London.

Mothers Accused and Abused is an important book about women and mothers who were accused of harming and sometimes killing their children. Many of these women lost one or several of their children to the care system. As the care system focuses on children, once these are removed, the parents and mothers are often left to deal with their feeling of loss on their own. As one of the women quoted in the book says, "Every time they take a baby away, the only way that I can deal with the pain of the loss is to get pregnant again as soon as possible". Unfortunately, without dealing with the problems that led to the child being taken from the mother, it is very possible that her next child will also be taken from her. "This makes no sense and must change", explains the editor of the book, Angela Foster, a psychiatric social worker, a psychoanalytic psychotherapist, supervisor and consultant working with clinical teams and individuals in mental health, forensic, substance misuse and childcare services. The book examines some of the many limitations and shortfalls in the ways in which professionals too often respond to these women, much due to contemporary budgetary and organisational pressures. The endemic emphasis on 'hitting targets' and 'closing cases' among other factors leads practitioners to avoid dealing with some of the more loaded, negative and often unconscious emotional content carried by these women due to the multiple traumas and adversities they experienced. This undealt with negative emotional content has a destructive potential, for these women, for their children and for the staff working with them. This destructive potential and the ways practitioners are trying to deal with it are skilfully illustrated by the authors through a series of well analysed and presented case studies. The book comprises of 13 chapters. Angela Foster, the editor, wrote the introduction and two other chapters and co-wrote the concluding chapter. The rest of the chapters were written by a wide range of authors practising in this area but coming from varying backgrounds, including nurses, occupational therapists, social workers, psychotherapists, psychologists and psychiatrists as well as legal specialists. This wide range of professional perspectives provides an excellent understanding of the journeys these women often go through and the efforts as well as challenges experienced by practitioners working with them. The book's perspective is psychodynamic and as such it provides a thorough analysis of some of the key emotional manifestations common in working with women in such situations. The chapters are short and written in an approachable language and the case studies make it easier to follow and understand, including for those without psychodynamic or psychoanalytic training. The book is aimed both at students and much more experienced practitioners and both could benefit from its richness. One of the many wonderful chapters describes a very slow and difficult process of engaging with and gaining the trust of a woman prisoned in a Mother and Child Unit. While initially she joined sessions only under the pressure of social services and the fear that her child might be taken away from her, upon her release from prison she was able to reflect on how the sessions helped her change as a person. During a period in which social services are called to fasten their belts and time frames, this book reminds us that in order to avoid the revolving door and these women repeatedly returning to the system when they become pregnant, a much more thorough approach is required in order to address the underlying issues affecting them. Some of the chapters focus more on the women or the work practitioners have done with them while others are focused on staff and the challenges that they may face. Other chapters highlight examples of inspiring practice including a 
chapter on the Family Drug and Alcohol Court and its achievements. The book is sensitive to cultural perceptions in relation to gender and femininity and the stereotypical expectations society has in relation to women and mothers, and what emotions and expressions are 'allowed' and permitted to them. Any book can cover just as much so we can only hope that future contributions to this area will also explore the place of class, race and ethnicity as data shows women from working class and ethnic minorities are much more likely to have their children taken away. It would also be good to hear the direct voices of these women by including them as authors or co-authors. 